\title{
The Neurovisceral and Electrodiagnostic Evaluation of Patients with Thoracic Spinal Cord Injury*
}

\author{
Michael E. Glick, M.D., Scott Haldeman, M.D., Ph.D., and Hooshang \\ Meshkinpour, M.D. \\ Departments of Medicine and Neurology, Veterans Administration Medical Centre, \\ Long Beach, CA and The University of California, Irvine, California, U.S.A.
}

\begin{abstract}
Summary
We studied nine patients with complete thoracic spinal cord injury in order to investigate distal electrophysiologic and end organ function. Studies included motor and sensory nerve conduction velocities, spinal and cortical somatosensory evoked responses, bulbocavernosus reflex responses, cystometry and colonic compliance, motor and myoelectrical activity. These studies confirmed an intact peripheral nervous system, as well as normal nerve root, cauda equina, conus medullaris and distal spinal cord function. Cystometry demonstrated decreased bladder capacity and inability to suppress detrusor contractions. Colonic compliance was greatly reduced, compared to control subjects. While basal colonic motor and myoelectrical activity was normal, these spinal cord injury patients failed to demonstrate the postprandial increase in colonic motor and myoelectric activity seen in normal subjects. These tests allow the clinician to define and document the extent of neuronal injury distal to a transverse myelopathy and to evaluate visceral end organ function.
\end{abstract}

Key words: Spinal cord injury; Myelopathy, Colonic motility, Cystometry, Neurovisceral evaluation.

\section{Introduction}

Urinary bladder dysfunction is a well recognized cause of morbidity and mortality in patients with demyelinating myelopathies, traumatic spinal cord injury and tumors and other forms of transverse myelopathies (Bors, 1957; Rossier \& Bors, 1964; Rossier \& Ott, 1974; Yalla et al., 1975 \& 1976). Severe constipation, however, is an equally debilitating symptom requiring daily manual disimpaction. The pathophysiology of colonic dysfunction in the spinal cord injury patient remains unclear.

Recent technical advances permit the definition and documentation of

* This paper was presented at the American Academy of Neurology Annual Meeting, Boston, 1984. Correspondence to: Michael E. Glick, M.D., Medical Service (111G), Veterans Administration Medical Centre, 5901 East Seventh Street, Long Beach, California 90822, U.S.A. 
peripheral nerve, nerve root, cauda equina, conus medullaris and distal spinal cord function as well as bladder and colonic dysfunction. Although cystometry has been thoroughly evaluated (Bors, 1957; Rossier \& Bors, 1964; Rossier \& Ott, 1974; Yalla et al., 1975 \& 1976) and colonic compliance (Meshkinpour et al., 1983) and motor activity (Connell et al., 1963) have been found to be abnormal in patients with spinal cord injury, these tests have not been correlated with electrodiagnostic studies to define the nature and extent of the neuronal lesions.

In order to correlate neuronal injury with end organ function, we studied a series of patients with well defined traumatic thoracic transverse myelopathies, utilizing extensive electrodiagnostic tests, cystometry, colonic compliance and colonic motor and myoelectrical studies.

\section{Methods}

\section{Patients and Subjects}

Nine patients with a clinical transverse myelopathic syndrome between $T_{6}$ and $\mathrm{T}_{12}$ were studied. All were male between 22 and 58 years in age and had sustained a traumatic spinal cord injury between three months and twenty years prior to investigation. All had anhydrosis and motor and sensory deficits in a distribution consistent with complete spinal cord injury within one dermatome of their vertebral spine injury. All had symptoms of bladder dysfunction and all had severe constipation, requiring manual disimpaction.

For each study, normal values were obtained by studying at least ten volunteers who were asymptomatic for neurologic, urologic and gastrointestinal disease. Normal values for somatosensory evoked responses from the pudendal and posterior tibial nerves, as well as for the bulbocavernosus reflex response, have been previously published (Haldeman et al., 1982).

The following studies were performed on each patient or control subject:

Motor and sensory nerve conduction velocities. Peripheral motor nerve conduction was studied in the posterior tibial nerve by recording potentials in the abductor hallucis muscle on stimulation of the posterior tibial nerve at the ankle and at the popliteal fossa (Goodgold \& Eberstein, 1972). Conduction velocities and distal latencies were calculated. Peripheral sensory nerve conduction was studied in an orthodromic fashion by stimulation of the sural nerve at the ankle and recording over the midcalf. The distal latency, amplitude and conduction velocity was assessed by computer averaging of 16 responses.

Bulbocavernosus reflex responses. Bulbocavernosus reflex responses were studied by stimulating the dorsal nerve of the penis with ring electrodes while recording potentials in the pelvic floor muscles with a surface electrode placed in the mid perineum and a reference electrode placed over the iliac creast (Haldeman et al., 1982). The latency of the response was assessed by computer averaging of 100 responses. Each study was performed three times to ensure reproducibility.

Somatosensory evoked potentials. Somatosensory evoked potentials were recorded on stimulation of the posterior tibial nerve at the ankle (Jones \& Small, 1978). Spinal cord potentials were recorded by means of surface electrodes placed 
at the $\mathrm{L}_{1}$ level with the reference electrode at the $\mathrm{L}_{5}$ spinous process. Cortical potentials were recorded over the scalp in the midline $2 \mathrm{~cm}$ behind the $\mathrm{C}_{\mathbf{z}}$ electroencephalographic recording site and referenced to the forehead. The averaged response to 1000 stimuli was recorded and each study was performed three times to ensure reproducibility. Somatosensory evoked responses were recorded from the same spinal and scalp locations upon stimulation of the dorsal nerve of the penis, a branch of the pudendal nerve.

Cystometrograms. Cystometry was performed by introducing carbon dioxide into the bladder through a transurethral catheter at a rate of $150 \mathrm{ml} / \mathrm{min}$ while recording intravesicular pressure. The onset of detrusor contraction, as marked by a rapid rise in intravesicular pressure, was determined. The ability of the patients to voluntarily suppress the detrusor contraction was assessed ( $\operatorname{Raz} \&$ Bradley, 1979).

Colonic Compliance. Following an overnight fast, tap water was allowed to gravity drain into the rectum at the rate of $100 \mathrm{ml} / \mathrm{min}$ while intracolonic pressure was monitored continuously. Each recording was continued until either a maximum of $2400 \mathrm{ml}$ of tap water was instilled or a maximum intracolonic pressure of $40 \mathrm{mmHg}$ was recorded (Connell et al., 1963; Glick et al., 1982; Haldeman et al., 1982).

Colonic motor and myoelectrical activity. Colonic motor and myoelectrical activity was recorded as previously described, utilizing a pressure transducer and a bipolar suction electrode assembly (Glick et al., 1982). Intraluminal pressure, myoelectrical signals, and pneumogram were recorded on a rectilinear recorder and an FM tape recorder. The motor activity of the rectosigmoid area was quantified by determining the mean amplitude of the colonic pressure over 15 min intervals. Myoelectrical signals were filtered, allowing only spike activity to be recorded. Myoelectrical activity was expressed as spike frequency per 15 minute interval. After a baseline mean amplitude motor activity and myoelectrical spike potential frequency was determined, each subject received a $1000 \mathrm{kcal}$ meal and recording continued for 90 minutes.

Statistical analysis was made with paired and unpaired Student's t-tests. All values are expressed as mean \pm standard error of the mean.

\section{Results}

Motor and Sensory Nerve Conduction Velocities: Motor and sensory nerve conduction velocities were obtained from the lower extremities in all nine spinal cord injury patients. All patients had normal motor and sensory nerve conduction velocities, amplitudes and distal latencies.

Bulbocavernosus Reflex Responses: Bulbocavernosus reflex responses were easily elicited in all nine spinal cord injury patients and demonstrated normal latencies to the onset of the response $(28-46 \mathrm{msec})$. A representative study appears in Figure 1.

Somatosensory Evoked Potentials: In normal volunteers, spinal and cortical evoked potentials upon stimulation of the posterior tibial and pudendal nerves can be easily and reproducibly elicited (Haldeman et al., 1982). In the nine spinal cord injury patients, 6 had normal spinal evoked responses on stimulation of the posterior tibial nerve, demonstrating normal somatosensory 


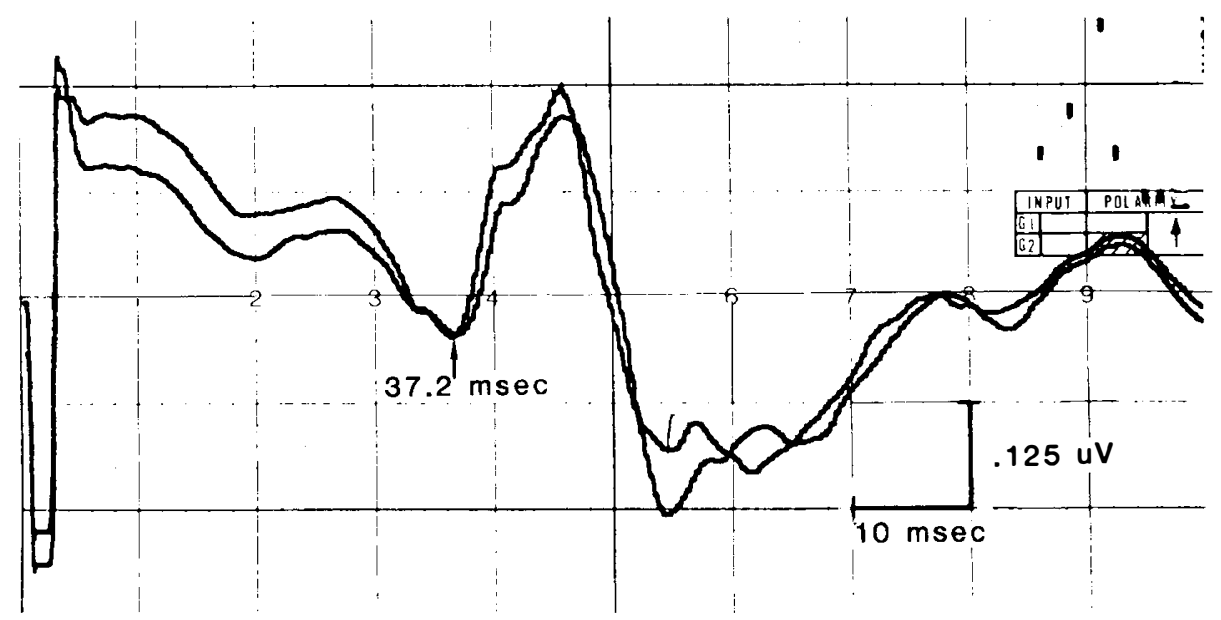

Figure 1. A representative bulbocavernosus reflex response from a spinal cord injury patient.

nerve conduction from the posterior tibial stimulation site to the recording site at the $\mathrm{L}_{1}$ region of the spinal cord. In three spinal cord injury patients, posterior tibial somatosensory evoked responses could not be detected at the $\mathrm{L}_{1}$ region of the cord. This was assumed to be due to obesity (Haldeman et al., 1982). All nine spinal cord injury patients had absent cortical somatosensory evoked responses upon stimulation of the posterior tibial nerve, as well as upon stimulation of the pudendal nerve.

Cystometrograms: In all nine spinal cord injury patients, the cystometrograms were markedly abnormal. Seven of these patients had a hyper-reflexic cystometrogram, with a marked increase in intravesicular pressure at volumes less than 150 millilitres of $\mathrm{CO}_{2}$, and were unable to inhibit the detrusor reflex. The other two patients demonstrated an areflexic cystometrogram.

Colonic Compliance: Seven of the spinal cord injury patients demonstrated an abnormal colonic compliance. In these patients, a rapid pressure rise was observed upon installation of a small volume of water. In two patients, an adequate seal between an occluding balloon and the rectum could not be maintained and colonic volume-pressure curves could not be recorded. In Figure 2 , representative tracings of a colonic compliance curve from a normal volunteer and from a spinal cord injury patient are demonstrated. The mean intracolonic pressure recorded at each infusion increment was greater in the spinal cold injury group than in the control group $(\mathrm{p}<0.01)$.

Colonic motor and myoelectrical activity: The mean amplitude of the colonic motor activity for each fifteen minute period from eleven control subjects and the nine spinal cord injury patients is shown in Figure 3. In the normal volunteers, there was an increase in the postprandial motor activity compared to the baseline $(\mathrm{p}<0.01)$. However, in the spinal cord injury patients, there was no significant increase in the motor activity after the meal. The colonic myoelectrical spike potential frequencies recorded in the normal controls and in the spinal cord injury patients are displayed in Figure 4. Coincident with the increase in the mean amplitude of colonic motor activity, normal control subjects 


\section{COLONIC COMPLIANCE}

\section{Normal}

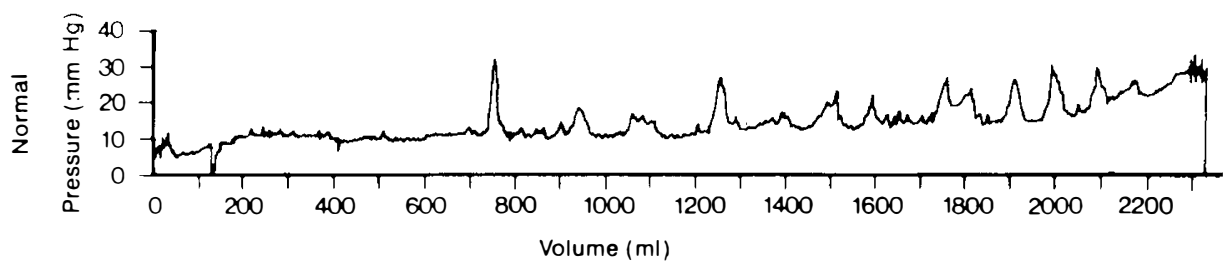

SCI

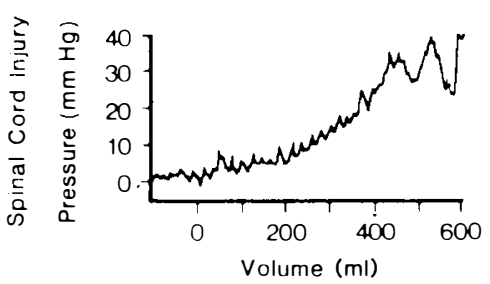

Figure 2. Colonic compliance curves from a normal (top) and a representative spinal cord injury patient (bottom).

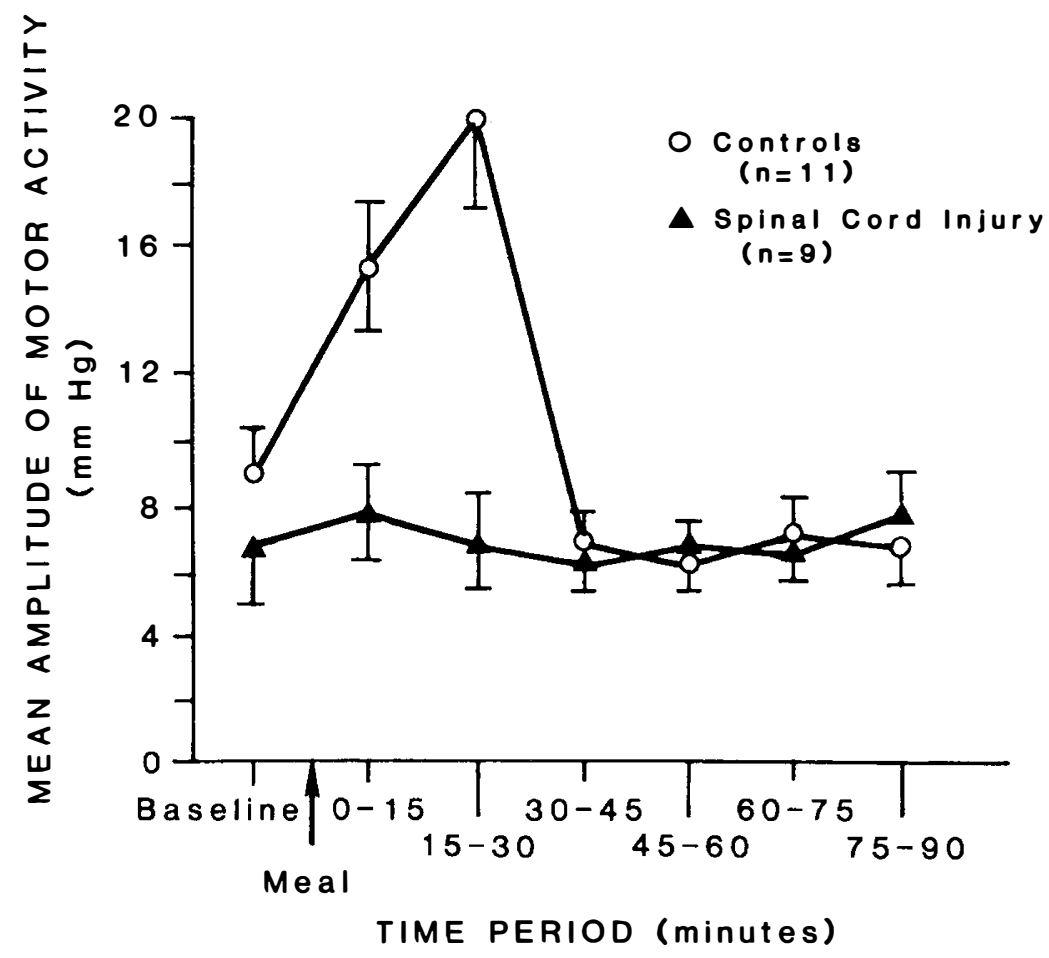

Figure 3. Mean amplitude of the colonic motor activity from 9 thoracic spinal cord injury patients is compared with the results from 11 control subjects. 


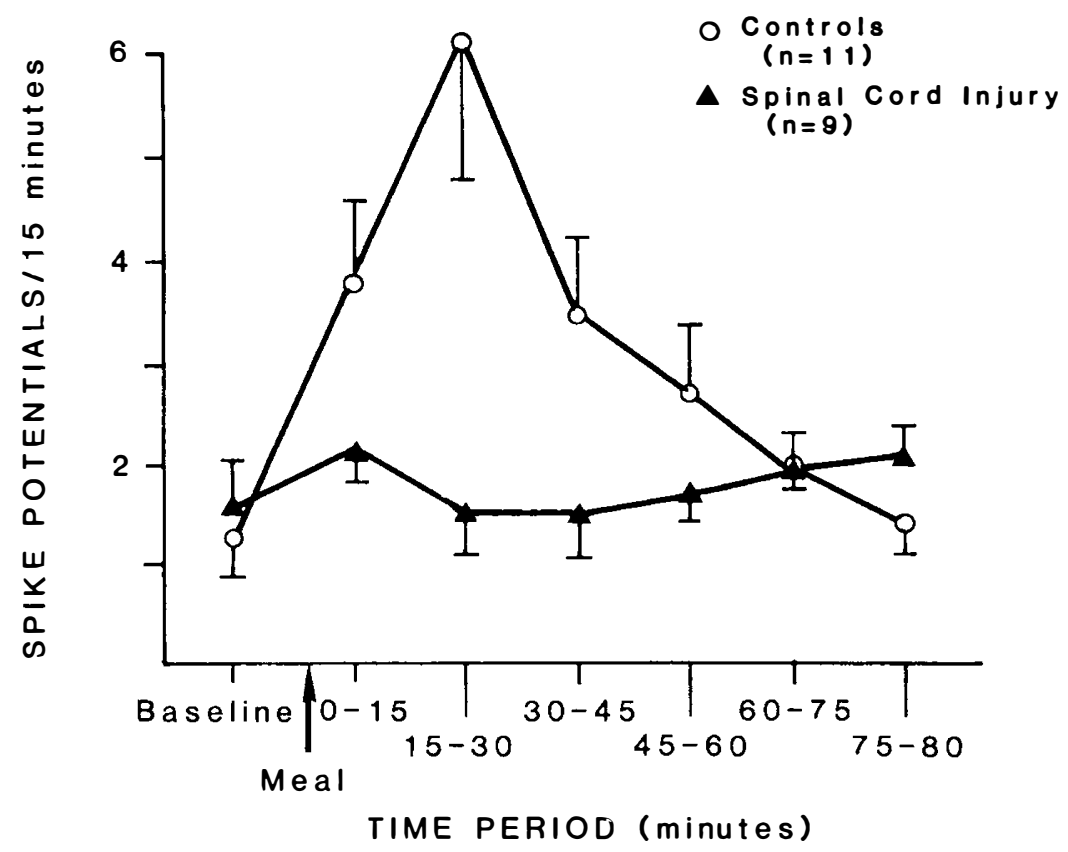

Figure 4. Colonic myoelectrical spike potential frequency from 9 thoracic spinal cord injury patients is compared with the results from 11 control subjects.

demonstrated a post-prandial increase in spike potential frequency $(p<0.01)$. However, in the spinal cord injury patients, the frequency of spike potentials did not change after the meal.

\section{Discussion}

The clinical evaluation of a spinal cord injury patient includes the determination of a sensory, motor and visceral level of neuronal interruption. However, it is difficult to assess the integrity of the neuronal structures or end organ function distal to the level of myelopathy. The presence of a high spinal cord lesion does not exclude a second lower lesion, either in the spinal cord or the peripheral nerves, but does make the clinical detection of such lesions difficult. A second distal lesion may significantly alter the nature and the management of end organ dysfunction. The use of the diagnostic tests in this study can facilitate the evaluation of neuronal and end organ function distal to the level of injury.

Peripheral motor and sensory nerve conduction studies assess peripheral nerve function. The integrity of the pudendal nerve, cauda equina and conus medullaris is evaluated by means of the bulbocavernosus reflex response (Dick et al., 1974; Ertekin \& Reel, 1976; Haldeman et al., 1982; Siroky et al., 1979). The pudendal and pelvic nerves provide a major portion of the innervation to bladder, distal colon and sexual organs. The integrity of the posterior columns of the spinal cord is evaluated by cortical recordings of evoked potentials from lower extremity nerves (Cusick et al., 1979; Eisen \& Elleker, 1980; Jones \& Small, 1978). The presence of a normal spinal evoked response suggests an intact peripheral and 
lumbosacral sensory pathway. In the presence of a normal spinal evoked response, the absence of a cortical response confirms the interruption of posterior column conduction between the $\mathrm{L}_{1}$ spine (where the signal is present) and the cortex (where the signal is absent). Since it has been suggested that the posterior tibial and pudendal cortical evoked responses may follow different central or spinal cord pathways (Haldeman et al., 1982), it may be of value to perform both of these tests, especially in the presence of an incomplete spinal cord injury. In our spinal cord injury patients, the peripheral nerves, cauda equina and distal spinal cord were intact and no transmission to the cortex was detectable, suggesting a complete thoracic transverse myelopathy. The abnormal cystometrograms, colonic compliance curves, and colonic motor and myoelectrical studies suggest disruption of ascending and descending pathways within the spinal cord.

Detrusor hyper-reflexia is the most common cystometric disturbance described in spinal cord injury (Bors, 1957; Rossier \& Bors, 1964; Rossier \& Ott, 1974; Yalla et al., 1975; Yalla et al., 1976). The contraction of the urinary bladder in response to distention is mediated by a spinal reflex mechanism. In normal individuals, this reflex is inhibited by input from higher centres in the brain (Barrington, 1921; Kuru, 1965). The interruption of descending spinal pathways causes contractions of the bladder in the presence of smaller than normal degrees of organ distention and prevents voluntary suppression of these contractions (Bradley, 1975; Kuru, 1965). Two of our spinal cord injury patients demonstrated detrusor areflexia. However, detrusor areflexia has been attributed to damaged innervation of the detrusor muscle from recurrent bladder infections and overdistention (Bradley et al., 1967; Raz \& Bradley, 1979) which may be related to bladder neck obstruction from detrusor hypertrophy or cystosphincteric dyssynergia (Yalla et al., 1975; Yalla et al., 1976). In our patients with spinal cord injury, the combination of abnormal cortical somatosensory evoked response studies and abnormal cystometrograms suggests interruption of both ascending somatosensory and descending visceral pathways between the lumbar spinal cord and the cortex. In patients with detrusor areflexia, the need to exclude a peripheral neuropathy and/or cauda equina or pudendal nerve lesions is evident (Bradley et al., 1967).

Study of colonic compliance to assess end organ function after neurologic injury was first described in 1940 (White et al., 1940). These studies suggested that lesions of the motor fibres in the brain or descending spinal tracts were associated with 'hyper-reflexic' or rapid rise volume-pressure curves, while lesions in the sacral segments of the cauda equina or pelvic plexus caused an 'areflexic' or flat volume-pressure curve. Studies in the cat (Scott \& Cantrell, 1949) confirmed these observations. A recent report (Connell et al., 1963) confirmed this decrease in colonic compliance in patients with evidence of traumatic transverse thoracic spinal cord injury on clinical examination. In our thoracic spinal cord injury patients, the increased slope of the colonic volumepressure curves was analagous to the hyper-reflexic cystometrograms, suggesting the same neuropathophysiology. Similar correlation between cystometry and colonic compliance has been documented in patients with spinal cord lesions secondary to multiple sclerosis (Glick et al., 1982).

To assess colonic motor activity in these patients, motor and myoelectrical 
activity were recorded in a resting state and after ingestion of a meal. The spinal cord injury patients failed to demonstrate the postprandial increase in colonic motility observed in the control population. Spike potentials represent the electrical manifestations of smooth muscle contraction and, hence, the myoelectrical spike potential frequency can be expected to parallel the motor activity. The spinal cord injury patients failed to demonstrate a postprandial increase in spike potential frequency. Thus, these myoelectrical recordings confirmed the measurements of colonic motor activity.

Several studies suggest that both the central (Glick et al., 1982) and peripheral (Battle et al., 1980) nervous system must be intact to mediate the normal postprandial colonic motor and myoelectrical response. In this study, electrophysiologic documentation of normal peripheral nerve conduction suggests that central ascending and/or descending pathways within the spinal cord must be intact for normal colonic end organ function.

In patients with a clinical examination compatible with a complete myelytic syndrome in the $T_{6}$ to $T_{12}$ region, peripheral motor and sensory nerve conduction velocities, somatosensory and bulbocavernosus evoked responses, cystometry and colonic compliance, motor and myoelectrical studies can define and document somatic nerve, urinary bladder and colonic function below the level of the cord lesion. We speculate that the utilization of these tests in less well defined neurologic injury such as incomplete spinal cord injuries, multiple sclerosis, cauda equina and nerve root lesions may elucidate the extent of neuronal lesions and detect subclinical visceral end organ dysfunction.

\section{Résumé}

Nous avons étudié neuf souffrants à la blessure thoracique intégrale de la moelle épinière pour investiguer la fonction électrophysiologique distale et celle d'organe d'en bout. Les études comprenaient vélocités de conduction des nerfs moteurs et sensoires, réponses évoquées somatosensoires tant vertébrales que corticales, réponses de réflexe bulbocaverneux, cystométrie et élasticité colonique, activité motrice et myoélectrique. Ces études ont confirmé un système nerveux périphérique intact, ainsi qu'une fonction normale de racine de nerf, de queue de cheval, de cône médullaire de même qu'une fonction distale normale de la moelle épinière. La cystométrie a démontré une capacité de vessie réduite et une incapabilité de supprimer les contractions à détrusion. L'élasticité colonique était réduite de beaucoup en comparaison avec les sujets de contrôle. Tandis que l'activité motrice et myoélectrique colonique de base était normale, ces souffrants à la blessure de la moelle épinière manquaient de démontrer l'augmentation postprandiale de l'activité motrice et myoélectrique colonique que l'on rencontre chez les sujets normaux. Ces essais permettent au clinicien de définir et de documenter l'étendue de la blessure neuronale distale à une myélopathie transversale et d'évaluer la fonction viscérale d'organe d'en bout.

\section{Zusammenfassung}

Wir haben neun Patienten mit vollständiger Brustkorb-Rückenmarkverletzung studiert, um distale elektrophysiologische und Endorganen-Funktion zu untersuchen. Die Studien umfassten Motorund Sensornerven-Leitungsgeschwindigkeiten, somatosensorische ausgelöste Wirbel- und RindenAntworten, Zystometrie und Dickdarmelastizität, Motor- und myoelektrische Tätigkeit. Diese Studien haben ein unbeschädigtes peripherisches Nerven- und myoelektrisches System bestätigt, wie auch normale Funktion von Nervenwurzeln, Pferdeschweif, Markzapfen, sowie eine normale distale Rüchenmarkfunktion. Die Zystometrie hat verminderte Blasenkapazität und Unfähigkeit, Detrusorkontraktionen zu unterdrücken, beweist. Dickdarmelastizität wurde im Vergleich mit normalen Subjekten viel vermindert. Während basale Motor- und myoelektrische Dickdarmtätigkeit normal war, haben diese Rückenmarkverletzungspatienten versäumt, die nach dem Mittagessen stattfindende Vergrösserung der Motor- und myoelektrischen Dickdarmtätigkeit zu beweisen, die man bei 
normalen Subjekten findet. Diese Versuche erlauben es dem Kliniker, den Umfang der zur quer laufenden Myelopathie distalen Neuronenverletzung zu bestimmen und die Eingeweiden-Endorganenfunktion zu bewerten.

\section{References}

BARRINGTON FJF 1921 The relation of the hind-brain to micturition. Brain 44:23.

Battle WM, SNape WJ, Alavi A, et al. 1980 Colonic dysfunction in diabetes mellitus. Gastroenterology 79:1217-1221.

BORS E 1957 Neurogenic bladder. Urological Survey 7:177-250.

Bradley WE, Chou S, Markland C 1967 Classifying neurologic dysfunction in the urinary bladder. In: The Neurogenic Bladder, p. 139-146, Boyarsky S, Ed., Williams and Wilkins Co., Baltimore.

Bradley WE, Timm GW, Scott FB 1975 Cystometry II: Central nervous system organization of detrusor reflex. Urology 5:578-580.

Connell AM, Frankel H, Guttmenn L 1963 The motility of the pelvic colon following complete lesions of the spinal cord. Paraplegia 1:98-115.

Cusick JF, Myklebest JB, Larson SJ, Sances A 1979 Spinal cord evaluation by cortical evoked responses. Archives of Neurology 36:140-3.

Dick HC, Bradley WE, Scott FB, et al. 1974 Pudendal sexual reflexes: Electrophysiologic investigations. Urology 3:376-379.

EISEN A, ElleKer G 1980 Sensory nerve stimulation and evoked cerebral potentials. Neurology 30:1097-1105.

ERTEKIN C, ReEL F 1976 Bulbocavernosus reflex in normal men and in patients with neurogenic bladder and/or impotence. Journal of the Neurological Sciences 28:1-15.

Glick ME, Meshrinpour H, Haldeman S, et al. 1982 Colonic dysfunction in multiple sclerosis. Gastroenterology 83:1002-1007.

Goodgold J, Eberstein A 1972 Electrodiagnosis of Neuromuscular disease. Williams and Williams Co., Baltimore, MD.

Haldeman S, Bradley WE, Bhatia NN, et al. 1982 Pudendal evoked responses. Archives of Neurology 39:280-283.

Haldeman S, Glick M, Bhatia ND, et al. 1982 Colonometry, cystometry and evoked responses in multiple sclerosis. Archives of Neurology 39:698-701.

JONES SJ, SMALL DG 1978 Spinal and sub-cortical evoked potentials following stimulation of the posterior tibial nerve in man. EEG Clinical Neurophysiology 44:299-306.

KURU M 1965 Nervous control of micturition. Physiological Reviews 45:425-94.

Meshrinpour H, Nowroozi F, Glick ME 1983 Colonic compliance in patients with spinal cord injury. Archives of Physical Medicine and Rehabilitation 64:111-112.

RAZ S, BRADLEY WE 1979 Neuromuscular dysfunction of the lower urinary tract. In: Harrison JH, Gilles RF, Perlmutter AD, et al., eds. Cambell's Urology. Philadelphia: W. B. Saunders, Co. 1215-1272.

Rossier A, Bors E 1964 Detrusor responses to perineal and rectal stimulation in patients with spinal cord injuries. Urologia Internationalis 18:181-190.

Rossier AB, OTt R 1974 Urinary manometry in spinal cord injury. British Journal of Urology 46:439-448.

Scott HW, Cantrell JR 1949 Colonometrographic studies of the effects of section of the parasympathetic nerves of the colon. Bulletin of Johns Hopkins Hospital 85:310-319.

Siroky MB, SAX DS, KRANE RJ 1979 Sacral signal tracing: The electrophysiology of the bulbocavernosus reflex. Journal of Urology 122:661-664.

White JC, Verlot MC, Ehrentheil O 1940 Neurogenic disturbances of the colon and their investigation by the colonometrogram. Annals of Surgery 112:1042.

YALla SV, Rossier AB, FAM B 1975 Synchronous cystosphincterometry in patients with spinal cord injury. Urology 6:777-778.

YALla SV, RossieR AB, FAM B 1976 Dyssynergic vesicourethral responses during bladder rehabilitation in spinal cord injury patients: Effects of suprapubic percussion, crede method and bethanechol chloride. Journal of Urology 115:575-578. 